\title{
Exploring the Isomer Dependent SERS Spectra of (diphenylphosphoryl)(pyridin-2, -3, and -4-yl)methanol Adsorbed on Gold Nanocolloids
}

\author{
Ewa Pięta, ${ }^{1}$ Edyta Proniewicz, ${ }^{2}$ Bogdan Boduszek, ${ }^{3}$ Tomasz K. Olszewski, ${ }^{3}$ \\ Younkyoo Kim, ${ }^{4}$ and Leonard M. Proniewicz ${ }^{1}$ \\ ${ }^{1}$ Faculty of Chemistry, Jagiellonian University, ul. Ingardena 3, 30-060 Krakow, Poland \\ ${ }^{2}$ Faculty of Foundry Engineering, AGH University of Science and Technology, ul. Reymonta 23, 30-059 Krakow, Poland \\ ${ }^{3}$ Department of Organic Chemistry, Faculty of Chemistry, Wroclaw University of Technology, Wybrzeże Wyspiańskiego 27, \\ 50-370 Wroclaw, Poland \\ ${ }^{4}$ Department of Chemistry, Hankuk University of Foreign Studies, Yongin, Kyunggi-do 449-791, Republic of Korea
}

Correspondence should be addressed to Edyta Proniewicz; proniewi@agh.edu.pl

Received 2 September 2013; Accepted 2 March 2014; Published 29 May 2014

Academic Editor: Yizhuang Xu

Copyright (c) 2014 Ewa Pięta et al. This is an open access article distributed under the Creative Commons Attribution License, which permits unrestricted use, distribution, and reproduction in any medium, provided the original work is properly cited.

\begin{abstract}
The surface-enhanced Raman scattering (SERS) spectra of three aminophosphonate derivatives of pyridine: (diphenylphosphoryl)(pyridin-2-yl)methanol ( $\alpha$-Pyr), (diphenylphosphoryl)(pyridin-3-yl)methanol ( $\beta$-Pyr), and (diphenylphosphoryl)(pyridin-4yl)methanol ( $\gamma$-Pyr) were measured after immobilization onto colloidal gold surface. Changes in the wavenumber, broadness, and enhancement between the corresponding Raman and SERS bands allowed to deduce orientation of the $\alpha$-, $\beta$-, and $\gamma$-isomers $(\alpha$-, $\beta$-, and $\gamma$-refer to the position of the substituent relative to the ring nitrogen atom) of aminophosphonate derivatives of pyridine on the gold surface. Briefly, it was demonstrated that the $\alpha$-Pyr and $\beta$-Pyr show the same mode of adsorption, whereas the adsorption process of the $\gamma$-Pyr isomer differs in this regard that pyridine assists in the interaction with the gold surface.
\end{abstract}

\section{Introduction}

Aminophosphonic acids and their derivatives are very promising group of compounds due to their occurrence in organisms and numerous important biological activities [1]. Their biological capabilities are connected with the inter-action with metal ions [2]. In the last few years, there has been an increasing interest in the field of synthesis and investigation of pyridine aminophosphonic acids because of their potential and significant antitumor properties $[2,3]$. The previous study on aminophosphonate derivatives of pyridine has proved the high reactivity of aminophosphonate ligands bearing $N$-heterocyclic donor atom $[2,4]$. Consequently, it has been demonstrated that the nitrogen-containing heterocyclic compounds have a wide range of applications ranging from anticancer [5], antituberculosis [6], antiproliferation [7], to enzyme inhibitors or chelating agents for heavy metal ions [8]. Among the nitrogen-containing molecules, pyridine derivatives play an essential role in many areas; that is, they are used as vitamins like nicotinic acid and nicotinic acid amide, vitamin B, herbicides, and insecticides [9].

In this study, we investigated three aminophosphonate derivatives of pyridine, including (diphenylphosphoryl) (pyridine-2-yl)methanol ( $\alpha$-Pyr), (diphenylphosphoryl) (pyridin-3-yl)methanol ( $\beta$-Pyr), and (diphenylphosphoryl) (pyridin-4-yl)methanol ( $\gamma$-Pyr) (Table 1 shows molecular structures of these compounds) using surface-enhanced Raman scattering (SERS) technique. We focused on the spectral changes related to the different position of the substituent (1-(diphenylphosporyl)metanol) with respect to the pyridine nitrogen atom, in $\alpha$-, $\beta$-, and $\gamma$-position, respectively.

Raman spectroscopy is a very useful method in the field of chemical analysis because it provides information about the vibrational structure and adsorption mode occurring at the solid/liquid interface [10]. However, the Raman process has extremely small cross section which limits its application 
TABLE 1: Molecular structures of the investigated compounds.

Name
(diphenylphosphoryl)(pyridin-2-yl)methanol (diphenylphosphoryl)(pyridin-3-yl)methanol

[11]. This limitation can be overcome and strongly enhanced Raman spectra (by up to $10^{14}-10^{15}$ ) can be obtained when the molecule is adsorbed onto roughened or colloidal metal surface $[12,13]$. The tremendous increase of the SERS signal can be achieved with relatively few metals: $\mathrm{Ag}, \mathrm{Au}, \mathrm{Cu}$, and less frequently with $\mathrm{Pt}$ [14]. Generally, there are two major factors responsible for this enhancement. The first mechanism is due to the metal plasmon resonance excitation, which increases the local fields in close proximity to the roughened metal surface or metal nanoparticles. The second, less significant factors concern the chemical effects, in particular the metal-molecule charge-transfer transion and other changes due to the adsorption process [12]. Analysis of the SERS signal (enhancement, wavenumber, and broadness) due to the molecular fragment vibrations of the investigated compound is essential for description of the possible way in which the adsorbate can interact with the surrounding medium [15-20]. Thus, SERS is a great tool for low-level detection and analysis, even for the single molecule detection. In a broader sense, this technique can be used for studying transport phenomenon across biological membranes or the kinetics of charge-transfer processes at an electrochemically roughened substrate [14].

\section{Materials and Methods}

2.1. (Diphenylphosphoryl)(pyridin-2, -3, and -4-yl)methanol Synthesis. (Diphenylphosphoryl)(pyridin-2-yl)methanol, (diphenylphosphoryl)(pyridin-3-yl)methanol, and (diphenylphosphoryl)(pyridin-4-yl)methanol were synthesized according to a previously described procedure $[21,22]$. The purity and chemical structures of the samples were proved by
${ }^{1} \mathrm{H},{ }^{31} \mathrm{P}$, and ${ }^{13} \mathrm{C}$ NMR spectra and electrospray mass spectrometry analysis.

2.2. FT-Raman Measurements. The FT-Raman spectra were recorded using a Nicolet spectrometer (model NXR 9650) coupled with a liquid-nitrogen-cooled germanium detector. All spectra were acquired with a resolution of $4 \mathrm{~cm}^{-1}$ and 1000 scans were usually collected. The spectrometer was equiped with a continuum-wave $\mathrm{Nd}+3$ :YAG laser emitting light at $1064 \mathrm{~nm}$ with total output power of up to $200 \mathrm{~mW}$.

2.3. SERS Measurements. Colloidal gold nanoparticles (20 nm, concentration: $0,02 \mathrm{mg} / \mathrm{mL}$ in aqueous buffer, contains sodium citrate as stabilizer) were purchased from Sigma-Aldrich Co. (Poznan, Poland). Aqueous sample solutions were prepared by dissolving each compound in deionized water. The concentration of the sample before mixing with the colloid was adjusted to $10^{-4} \mathrm{M}$. Briefly, $20 \mu \mathrm{L}$ of the aqueous sample solution was added to $40 \mu \mathrm{L}$ of the gold colloid and stirred vigorously.

The SERS spectra of the investigated compounds were col lected three times with InVia Renishaw spectrometer equipped with an air-cooled charge-coupled device (CCD) detector. The spectral resolution was set at $4 \mathrm{~cm}^{-1}$. The continuous-wave diode laser (HP NIR) with the $785 \mathrm{~nm}$ excitation line was used as an excitation source. The laser power at the sample was set at $10 \mathrm{~mW}$.

All of the SERS spectra were recorded within one hour of adding the sample to the Au colloid. The obtained spectra were almost identical, except for small differences (up to 5\%) in some band intensities. No spectral changes that could be 


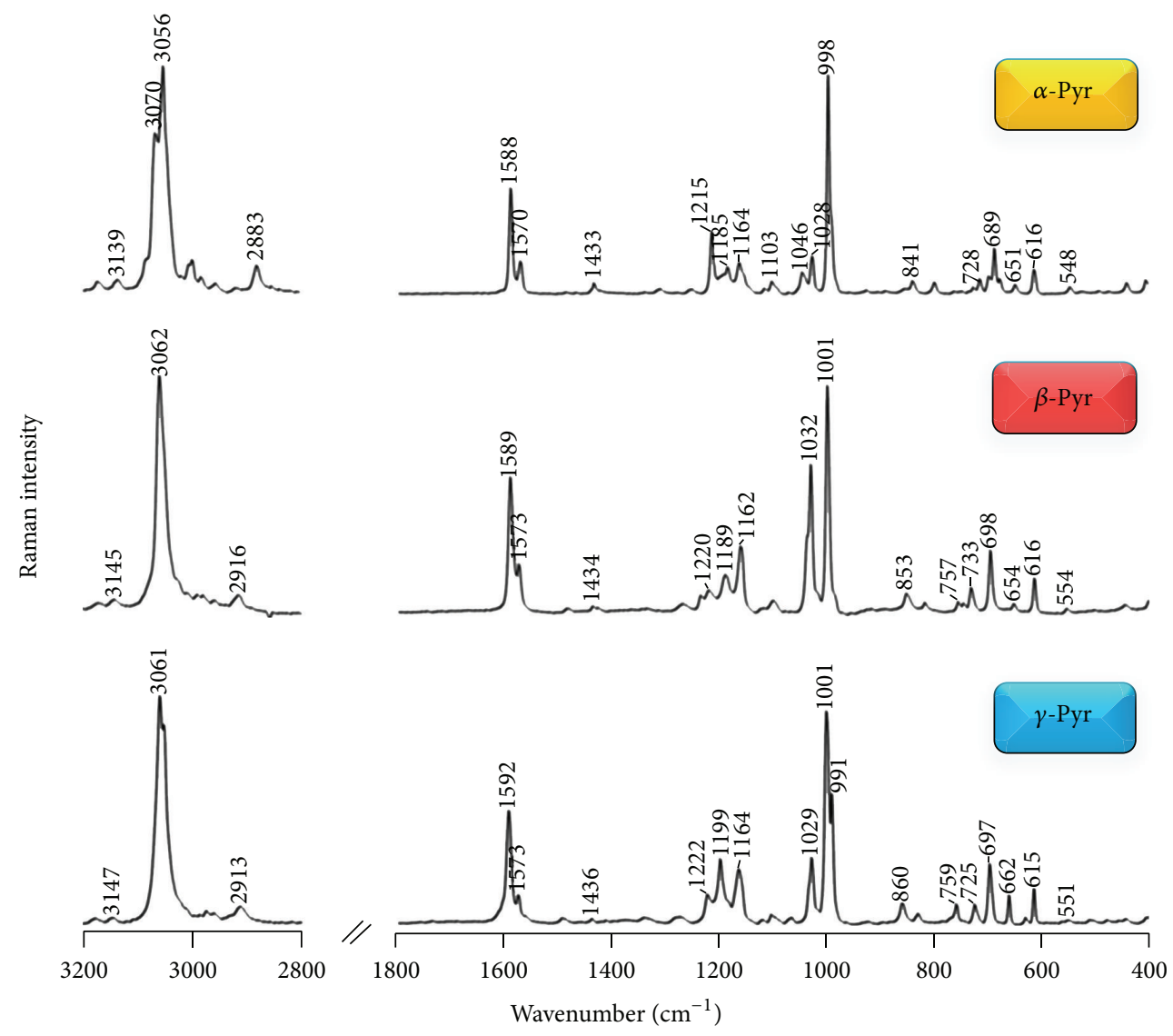

Figure 1: The FT-RS spectra of $\alpha$-Pyr, $\beta$-Pyr, and $\gamma$-Pyr in the spectral ranges of $3200-2800$ and $1800-400 \mathrm{~cm}^{-1}$.

associated with sample decomposition were observed during these measurements.

\section{Results and Discussion}

Figure 1 shows the FT-Raman spectra of the three aminophosphonate derivatives of pyridine: $\alpha$-Pyr, $\beta$-Pyr, and $\gamma$-Pyr, in the solid state in the spectral ranges between 3200-2800 and $1800-400 \mathrm{~cm}^{-1}$. Figure 2 presents the SERS spectra of these compounds in an aqueous gold sol. Table 2 summarized wavenumbers, full band widths at half maximum (FWHM), and proposed band assignments of the SERS bands together with those observed in the corresponding Raman spectra. The proposed band allocation to the normal mode motions is based on the density functional theory calculations performed for these molecules [23] and the Raman spectra of compounds that contain similar molecular fragments $[10,24-$ 32].

Comparison of the SERS (Figure 2) spectrum of each of the investigated pyridine $\alpha$-hydroxymethyl biphenyl phosphine oxides with the proper Raman spectrum (Figure 1) reveals similarity in the corresponding bands width and wavenumbers (see Table 2). However, few differences are noticeable in the enhancement of certain bands. These differences concern mainly the $1570\left[\nu_{8 \mathrm{~b}}\right], 1215\left[\nu_{9 \mathrm{a}}(\mathrm{Pyr})\right]$, $1046\left[\nu_{12}(\right.$ Pyr $\left.)\right]$, and $992 \mathrm{~cm}^{-1}\left[\nu_{1}\right.$ (Pyr) $]$ Raman and the $550\left[\gamma(\mathrm{CO})+\rho_{\mathrm{as}}(\mathrm{Phe})\right]$ and $530 \mathrm{~cm}^{-1}[\gamma(\mathrm{CO})+\rho$ $\left.(\mathrm{CP}=\mathrm{O})+\rho_{\mathrm{as}}(\mathrm{Phe})+\delta_{\text {oop }}(\mathrm{CC}(\mathrm{P}) \mathrm{C})\right]$ SERS bands (see Table 2 for detailed band wavenumbers). The former Raman spectral features are weak or absent in the SERS spectra. In addition, increase in the relative intensity of the 998 $\left[\nu_{12}(\mathrm{Phe})\right]$ and $1102 \mathrm{~cm}^{-1}\left[\nu(\mathrm{CO})+\nu\left(\mathrm{PC}_{\text {phe }}\right)\right]$ SERS signals and decrease in the $1588 \mathrm{~cm}^{-1}\left[\nu_{8 \mathrm{a}}\right]$ SERS band relative enhancement are evident for all the investigated molecules in comparison with those in the Raman spectra.

Group theory provides the most elegant framework to use of the aforementioned bands' relative intensity changes to predict the geometries of aromatic molecules adsorbed onto SERS-active substrates [33]. Under assumptions that the vibrations involving atoms close to the metal surface are enhanced due to their interactions with the metal surface, the "surface selection rules" for a perpendicular ring orientation designate the in-plane vibrations to be enhanced to a greater extent than the out-of-plane vibrations. The opposite should be the case for the horizontal adsorption geometry. In addition, according to the propensity rules of the electromagnetic mechanism of SERS, the strongest SERS bands of the perpendicular phenyl ring with respect to the metal surface are due to the $v_{12}$ mode [34]. Gao and Weaver reported that $\nu_{12}$ of alkylbenzenes shifts down by $10-15 \mathrm{~cm}^{-1}$ upon adsorption at the surface. In contrast, the observed downshift by $4-5 \mathrm{~cm}^{-1}$ for this mode of halogenobenzenes 


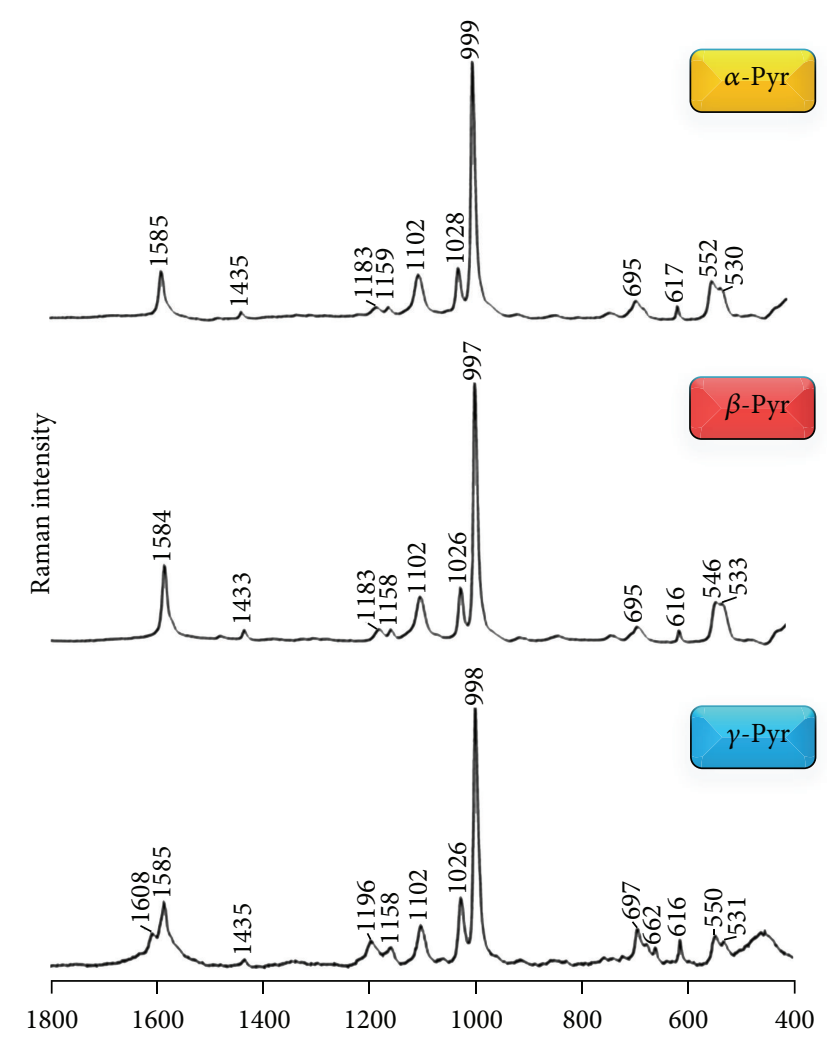

FIGURE 2: The SERS spectra of $\alpha$-Pyr, $\beta$-Pyr, and $\gamma$-Pyr adsorbed onto colloidal gold surface.

was interpreted as evidence of no direct interaction between the $\pi$-electron systems and the metal surface. Also, significant band broadening for the aromatic ring modes was reported in the case of $\pi$ adsorption caused by an interaction between the ring and the metal surface [35].

The foregoing "surface selection rules" and spectral changes as well as the c.a. $1590\left[v_{8 \mathrm{a}}\right]$, c.a. $1435\left[v_{19 \mathrm{~b}}\right]$, c.a. $1198\left[v_{9 \mathrm{a}}\right.$ and/or $\left.v_{\text {sym }}\left(\mathrm{C}_{\beta} \mathrm{C}_{\gamma} \mathrm{H}_{2} \mathrm{C}_{\delta}\right)\right]$, c.a. $1026\left[v_{18 \mathrm{a}}\right]$, c.a. $998\left[v_{12}\right]$, c.a. $695\left[v_{6 \mathrm{a}}\right]$, and c.a. $616 \mathrm{~cm}^{-1}\left[v_{6 \mathrm{~b}}\right.$ (Phe)] SERS signals imply an essentially perpendicular orientation of the phenyl rings of $\alpha$-Pyr, $\beta$-Pyr, and $\gamma$-Pyr on the colloidal gold nanoparticles, whereas the pyridine ring of these molecules is not involved in the adsorption process. However, considering the molecular structure of pyridine $\alpha$-hydroxymethyl biphenyl phosphine oxides, it seems unlikely that both the phenyl rings adopt the same vertical geometry with respect to the gold surface (one the $998 \mathrm{~cm}^{-1}$ band, FWHM $=9 \mathrm{~cm}^{-1}$ ). Thus, we postulate that only one of the equivalent phenyl rings is involved in the interaction with $\mathrm{Au}$. On the other hand, the moderate strengthening of the 1102,550 , and $530 \mathrm{~cm}^{-1}$ spectral features between the Raman and SERS spectra results from bonding interaction between $\mathrm{Au}$ and the $-\mathrm{OCP}(=\mathrm{O})$ molecular fragment. Therefore, the $\mathrm{O}-\mathrm{C}$ and $\mathrm{P}=\mathrm{O}$ bonds should adopt a tilted orientation with respect to the gold surface. Such an arrangement favors interaction of the oxygen atom's lone pair with the metal surface.

The modes at $1608\left[v_{8 \mathrm{a}}(\mathrm{Pyr})\right]$ and $662 \mathrm{~cm}^{-1}\left[\rho_{\mathrm{as}}(\mathrm{Pyr})\right.$ $\left.+\delta\left(\mathrm{C}_{\mathrm{pyr}} \mathrm{CO}\right)+\delta\left(\mathrm{C}_{\mathrm{pyr}} \mathrm{CP}\right)\right]$ distinguish the SERS spectrum of $\gamma$-Pyr from those of $\alpha$-Pyr and $\beta$-Pyr. The appearance of these two bands in the $\gamma$-Pyr SERS spectrum and the slight strengthening of the 1196 and $1158 \mathrm{~cm}^{-1}$ spectral features (see Table 2 for bands assignment) suggest that in the case of 4-isomer of $\alpha$-hydroxymethyl biphenyl phosphine oxide pyridine assists in the adsorption process of this molecule.

\section{Conclusions}

In this work, we discussed the mode of adsorption for three isomers (2-, 3-, and 4-) of pyridine $\alpha$-hydroxymethyl biphenyl phosphine oxide immobilized onto a colloidal gold surface. We demonstrated that the investigated molecules interact with the gold substrate surface through the phenyl ring that is oriented vertically in respect to the surface. For $\gamma$-Pyr, we suggested also that the pyridine ring located in the vicinity of the gold surface is able to assist in the adsorption process. Although the interaction of $\alpha$-Pyr, $\beta$-Pyr, and $\gamma$-Pyr with the gold surface was suggested by the phenyl ring, the hydroxyl $(-\mathrm{OH})$ and phosphonate oxygen $(=\mathrm{O})$ fragments assisted in this process.

\section{Conflict of Interests}

The authors declare that there is no conflict of interests regarding the publication of the paper. 
TABLE 2: Wavenumbers, full band widths at half maximum, and proposed band assignments for FT-RS and SERS spectra of $\alpha$-Pyr, $\beta$-Pyr, and $\gamma$-Pyr adsorbed onto colloidal gold surface.

\begin{tabular}{|c|c|c|c|c|}
\hline \multirow{2}{*}{ Mode } & \multicolumn{2}{|c|}{ FT-RS } & \multicolumn{2}{|c|}{ SERS Au colloid } \\
\hline & $\nu\left[\mathrm{cm}^{-1}\right]$ & FWHM $\left[\mathrm{cm}^{-1}\right]$ & $v\left[\mathrm{~cm}^{-1}\right]$ & FWHM $\left[\mathrm{cm}^{-1}\right]$ \\
\hline \multicolumn{5}{|c|}{$\alpha-\mathrm{Pyr}$} \\
\hline$\gamma(\mathrm{CO})+\rho(\mathrm{CP}=\mathrm{O})+\rho_{\mathrm{as}}(\mathrm{Phe})+\delta_{\mathrm{oop}}(\mathrm{CC}(\mathrm{P}) \mathrm{C})$ & 528 & 6 & 530 & 17 \\
\hline$\gamma(\mathrm{CO})+\rho_{\mathrm{as}}(\mathrm{Phe})$ & 548 & 7 & 552 & 14 \\
\hline$v_{6 \mathrm{a}}(\mathrm{Pyr})$ and $/$ or $v_{6 \mathrm{~b}}(\mathrm{Phe})$ & 616 & 7 & 617 & 6 \\
\hline$\rho_{\mathrm{as}}(\mathrm{Pyr})+\delta\left(\mathrm{C}_{\mathrm{pyr}} \mathrm{CO}\right)+\delta\left(\mathrm{C}_{\mathrm{pyr}} \mathrm{CP}\right)$ & 651 & 7 & - & - \\
\hline$v_{11}\left(\rho_{\mathrm{as}}(\mathrm{Pyr})\right)$ and $/$ or $v_{6 \mathrm{a}}\left(\mathrm{Phe} ; \delta_{\text {oop }}(\mathrm{CC}(\mathrm{H}) \mathrm{C})\right)$ & 689 & 6 & 695 & 17 \\
\hline$\nu_{10 \mathrm{~b}}\left(\rho_{\mathrm{t}}(\mathrm{Pyr})\right)$ and/or $\rho_{\mathrm{as}}(\mathrm{Phe})+\nu\left(\mathrm{PC}_{\mathrm{phe}}\right)$ & 728 & 3 & - & - \\
\hline$\nu_{10 \mathrm{a}}(\mathrm{Phe} ; \gamma(\mathrm{CH}))$ & 841 & 9 & - & - \\
\hline$\nu_{1}\left(\mathrm{Pyr} ; \delta_{\text {oop }}(\mathrm{CC}(\mathrm{H}) \mathrm{C})+\nu(\mathrm{CN})+\delta_{\text {trig }}(\mathrm{Pyr})\right)$ & 992 & 7 & - & - \\
\hline$v_{12}(\mathrm{Phe})$ & 998 & 5 & 999 & 9 \\
\hline$\nu_{18 \mathrm{a}}(\mathrm{Phe})$ & 1028 & 7 & 1028 & 9 \\
\hline$v_{12}(\mathrm{Pyr})$ & 1046 & 11 & - & - \\
\hline$\rho_{\mathrm{r}}(\mathrm{CC}(\mathrm{H}) \mathrm{C})_{\mathrm{pyr}}+\nu(\mathrm{CC})_{\mathrm{pyr}}+\nu(\mathrm{CO})+\nu\left(\mathrm{PC}_{\mathrm{phe}}\right)$ & 1103 & 9 & 1102 & 11 \\
\hline$\nu(\mathrm{P}=\mathrm{O})$ and $/$ or $\delta(\mathrm{CH})$ & 1164 & 6 & 1159 & 7 \\
\hline$\nu_{9 \mathrm{a}}(\mathrm{Phe} ; \delta(\mathrm{CH}))$ and/or $v_{\text {sym }}\left(\mathrm{C}_{\beta} \mathrm{C}_{\gamma} \mathrm{H}_{2} \mathrm{C}_{\delta}\right)$ & 1185 & 6 & 1183 & 18 \\
\hline$v_{9 \mathrm{a}}(\mathrm{Pyr})$ and/or $v_{7 \mathrm{a}}($ Phe; phenyl-C stretch $)$ & 1215 & 7 & - & - \\
\hline$v_{19 b}(\mathrm{Pyr} / \mathrm{Phe})$ & 1433 & 8 & 1435 & 8 \\
\hline$v_{8 \mathrm{~b}}(\mathrm{Pyr} / \mathrm{Phe})$ & 1570 & 10 & - & - \\
\hline$v_{8 \mathrm{a}}(\mathrm{Pyr} / \mathrm{Phe})$ & 1588 & 10 & 1585 & 9 \\
\hline \multicolumn{5}{|c|}{$\beta$-Pyr } \\
\hline$\gamma(\mathrm{CO})+\rho(\mathrm{CP}=\mathrm{O})+\rho_{\mathrm{as}}(\mathrm{Phe})+\delta_{\text {oop }}(\mathrm{CC}(\mathrm{P}) \mathrm{C})$ & 534 & 10 & 533 & 17 \\
\hline$\gamma(\mathrm{CO})+\rho_{\mathrm{as}}(\mathrm{Phe})$ & 554 & 7 & 546 & 14 \\
\hline$v_{6 \mathrm{a}}(\mathrm{Pyr})$ and $/$ or $v_{6 \mathrm{~b}}(\mathrm{Phe})$ & 616 & 6 & 616 & 6 \\
\hline$\rho_{\mathrm{as}}(\mathrm{Pyr})+\delta\left(\mathrm{C}_{\mathrm{pyr}} \mathrm{CO}\right)+\delta\left(\mathrm{C}_{\mathrm{pyr}} \mathrm{CP}\right)$ & 654 & 7 & - & - \\
\hline$v_{11}\left(\rho_{\mathrm{as}}(\mathrm{Pyr})\right)$ and $/$ or $v_{6 \mathrm{a}}\left(\mathrm{Phe} ; \delta_{\mathrm{oop}}(\mathrm{CC}(\mathrm{H}) \mathrm{C})\right)$ & 698 & 8 & 695 & 11 \\
\hline$\nu_{10 \mathrm{~b}}\left(\rho_{\mathrm{t}}(\mathrm{Pyr})\right)$ and $/$ or $\rho_{\mathrm{as}}(\mathrm{Phe})+\nu\left(\mathrm{PC}_{\mathrm{phe}}\right)$ & 733 & 6 & - & - \\
\hline$\gamma_{\text {as }}(\mathrm{Pyr})+\delta_{\text {oop }}(\mathrm{CC}(\mathrm{H}) \mathrm{C})_{\text {phe }}+\delta_{\text {oop }}\left(\mathrm{CC}_{\text {phe }}(\mathrm{P}) \mathrm{C}\right)$ & 757 & 7 & - & - \\
\hline$\nu_{10 \mathrm{a}}(\mathrm{Phe} ; \gamma(\mathrm{CH}))$ & 853 & 12 & - & - \\
\hline$\nu_{12}(\mathrm{Phe})$ & 1001 & 6 & 997 & 9 \\
\hline$\nu_{18 \mathrm{a}}(\mathrm{Phe})$ & 1032 & 8 & 1026 & 9 \\
\hline$v_{12}(\mathrm{Pyr})$ & 1041 & 7 & - & - \\
\hline$\rho_{\mathrm{r}}(\mathrm{CC}(\mathrm{H}) \mathrm{C})_{\mathrm{pyr}}+\nu(\mathrm{CC})_{\mathrm{pyr}}+\nu(\mathrm{CO})+\nu\left(\mathrm{PC}_{\mathrm{phe}}\right)$ & 1103 & 9 & 1102 & 10 \\
\hline$\nu(\mathrm{P}=\mathrm{O})$ and $/$ or $\delta(\mathrm{C}-\mathrm{H})$ & 1162 & 14 & 1157 & 9 \\
\hline$v_{9 \mathrm{a}}(\mathrm{Phe} ; \delta(\mathrm{CH}))$ and/or $v_{\text {sym }}\left(\mathrm{C}_{\beta} \mathrm{C}_{\gamma} \mathrm{H}_{2} \mathrm{C}_{\delta}\right)$ & 1189 & 19 & 1183 & 17 \\
\hline$\nu_{9 \mathrm{a}}(\mathrm{Pyr})$ and/or $\nu_{7 \mathrm{a}}($ Phe; phenyl-C stretch $)$ & 1220 & 20 & - & - \\
\hline$\nu_{19 b}(\mathrm{Pyr} / \mathrm{Phe})$ & 1434 & 8 & 1433 & 8 \\
\hline$v_{8 \mathrm{~b}}(\mathrm{Pyr} / \mathrm{Phe})$ & 1573 & 8 & - & - \\
\hline$\nu_{8 \mathrm{a}}(\mathrm{Pyr} / \mathrm{Phe})$ & 1589 & 8 & 1584 & 14 \\
\hline \multicolumn{5}{|c|}{$\gamma$-Pyr } \\
\hline$\gamma(\mathrm{CO})+\rho(\mathrm{CP}=\mathrm{O})+\rho_{\mathrm{as}}(\mathrm{Phe})+\delta_{\text {oop }}(\mathrm{CC}(\mathrm{P}) \mathrm{C})$ & 528 & 4 & 531 & 14 \\
\hline$\gamma(\mathrm{CO})+\rho_{\mathrm{as}}(\mathrm{Phe})$ & 551 & 9 & 550 & 14 \\
\hline$v_{6 \mathrm{a}}(\mathrm{Pyr})$ and $/$ or $v_{6 \mathrm{~b}}(\mathrm{Phe})$ & 615 & 5 & 616 & 5 \\
\hline$\rho_{\mathrm{as}}(\mathrm{Pyr})+\delta\left(\mathrm{C}_{\mathrm{pyr}} \mathrm{CO}\right)+\delta\left(\mathrm{C}_{\mathrm{pyr}} \mathrm{CP}\right)$ & 662 & 5 & 662 & 5 \\
\hline$\nu_{11}\left(\rho_{\mathrm{as}}(\mathrm{Pyr})\right)$ and $/$ or $\nu_{6 \mathrm{a}}\left(\mathrm{Phe} ; \delta_{\text {oop }}(\mathrm{CC}(\mathrm{H}) \mathrm{C})\right)$ & 697 & 9 & 697 & 8 \\
\hline$\nu_{10 \mathrm{~b}}\left(\rho_{\mathrm{t}}(\mathrm{Pyr})\right)$ and/or $\rho_{\mathrm{as}}(\mathrm{Phe})+\nu\left(\mathrm{PC}_{\mathrm{phe}}\right)$ & 725 & 9 & - & - \\
\hline$\gamma_{\mathrm{as}}(\mathrm{Pyr})+\delta_{\mathrm{oop}}(\mathrm{CC}(\mathrm{H}) \mathrm{C})_{\mathrm{phe}}+\delta_{\text {oop }}\left(\mathrm{CC}_{\mathrm{phe}}(\mathrm{P}) \mathrm{C}\right)$ & 759 & 5 & - & - \\
\hline$\nu_{10 \mathrm{a}}(\mathrm{Phe} ; \gamma(\mathrm{CH}))$ & 860 & 11 & - & - \\
\hline
\end{tabular}


TABLE 2: Continued.

\begin{tabular}{|c|c|c|c|c|}
\hline \multirow{2}{*}{ Mode } & \multicolumn{2}{|c|}{ FT-RS } & \multicolumn{2}{|c|}{ SERS Au colloid } \\
\hline & $\nu\left[\mathrm{cm}^{-1}\right]$ & FWHM $\left[\mathrm{cm}^{-1}\right]$ & $v\left[\mathrm{~cm}^{-1}\right]$ & FWHM $\left[\mathrm{cm}^{-1}\right]$ \\
\hline$v_{1}\left(\mathrm{Pyr} ; \delta_{\text {oop }}(\mathrm{CC}(\mathrm{H}) \mathrm{C})+\nu(\mathrm{CN})+\delta_{\text {trig }}(\mathrm{Pyr})\right)$ & 991 & 6 & - & - \\
\hline$v_{12}(\mathrm{Phe})$ & 1001 & 6 & 998 & 9 \\
\hline$v_{18 \mathrm{a}}(\mathrm{Phe})$ & 1029 & 9 & 1026 & 10 \\
\hline$\rho_{\mathrm{r}}(\mathrm{CC}(\mathrm{H}) \mathrm{C})_{\mathrm{pyr}}+\nu(\mathrm{CC})_{\mathrm{pyr}}+\nu(\mathrm{CO})+v\left(\mathrm{PC}_{\mathrm{phe}}\right)$ & 1103 & 8 & 1102 & 11 \\
\hline$\nu(\mathrm{P}=\mathrm{O})$ and $/$ or $\delta(\mathrm{C}-\mathrm{H})$ & 1164 & 15 & 1158 & 16 \\
\hline$v_{9 \mathrm{a}}(\mathrm{Phe} ; \delta(\mathrm{CH}))$ and/or $v_{\text {sym }}\left(\mathrm{C}_{\beta} \mathrm{C}_{\gamma} \mathrm{H}_{2} \mathrm{C}_{\delta}\right)$ & 1199 & 12 & 1196 & - \\
\hline$v_{9 \mathrm{a}}(\mathrm{Pyr})$ and/or $v_{7 \mathrm{a}}($ Phe; phenyl-C stretch $)$ & 1222 & 13 & - & - \\
\hline$v_{19 \mathrm{~b}}(\mathrm{Pyr} / \mathrm{Phe})$ & 1436 & 5 & 1435 & 9 \\
\hline$v_{8 \mathrm{~b}}(\mathrm{Pyr} / \mathrm{Phe})$ & 1573 & 8 & 1585 & 10 \\
\hline$v_{8 \mathrm{a}}(\mathrm{Pyr} / \mathrm{Phe})$ & 1592 & 11 & 1608 & 15 \\
\hline
\end{tabular}

\section{Acknowledgments}

This work was supported by the National Research Center (Grant no. N N204 544339 to E.P.). Younkyoo Kim gratefully acknowledges HUFS for financial support. Bogdan Boduszek and Tomasz K. Olszewski acknowledge financial support from a statutory activity subsidy from the Polish Ministry of Science and Higher Education for the Faculty of Chemistry, Wroclaw University of Technology.

\section{References}

[1] B. Lejczak and P. Kafarski, "Biological activity of aminophosphonic acids and their short peptides," in Phosphorous Heterocycles I, vol. 20 of Topics in Heterocyclic Chemistry, pp. 31-63, 2009.

[2] B. Zurowska, K. Ślepokura, U. Kalinowska-Lis, and B. Boduszek, "Synthesis, spectroscopy and magnetic properties of transition-metal complexes with diethyl [(n-butylamino$\mathrm{N}$ )(pyridin-2-yl)]methylphosphonate (2-pmape): structure of [Co(2-pmape)2](ClO4)2 complex," Inorganica Chimica Acta, vol. 384, pp. 143-148, 2012.

[3] E. D. Naydenova, P. T. Todorov, and K. D. Troev, "Recent synthesis of aminophosphonic acids as potential biological importance," Amino Acids, vol. 38, no. 1, pp. 23-30, 2010.

[4] B. Żurowska and B. Boduszek, "Synthesis, spectroscopy and magnetic properties of transition-metal complexes with aminophosphonate derivatives of pyridine," Materials SciencePoland, vol. 29, no. 2, pp. 105-111, 2011.

[5] G. Gakhar, T. Ohira, A. Shi, D. H. Hua, and T. A. Nguyen, "Antitumor effect of substituted quinolines in breast cancer cells," Drug Development Research, vol. 69, no. 8, pp. 526-534, 2008.

[6] S. N. Pandeya, A. S. Raja, and G. Nath, "Synthesis and antimicrobial evaluation of some 4- or 6-chloroisatin derivatives," Indian Journal of Chemistry B: Organic and Medicinal Chemistry, vol. 45, no. 2, pp. 494-499, 2006.

[7] M. Sedic, M. Poznic, P. Gehrig et al., "Differential antiproliferative mechanisms of novel derivative of benzimidazo[1,2$\alpha$ ]quinoline in colon cancer cells depending on their p53 status," Molecular Cancer Therapeutics, vol. 7, no. 7, pp. 2121-2132, 2008.

[8] T. K. Olszewski and B. Boduszek, "Application of bis(trimethylsilyl) phosphonite in the efficient preparation of new heterocyclic $\alpha$-aminomethyl-H-phosphinic acids," Synthesis, no. 3, Article ID T18810SS, pp. 437-442, 2011.

[9] Y. S. Higasio and T. Shoji, "Heterocyclic compounds such as pyrroles, pyridines, pyrollidins, piperdines, indoles, imidazol and pyrazins," Applied Catalysis A: General, vol. 221, no. 1-2, pp. 197-207, 2001.

[10] S. F. Simpson and J. M. Harris, "Raman spectroscopy of the liquid-solid interface: monolayer and bilayer adsorption of pyridine on silica," Journal of Physical Chemistry, vol. 94, no. 11, pp. 4649-4654, 1990.

[11] K. Kneipp, H. Kneipp, I. Itzkan, R. R. Dasari, and M. S. Feld, "Surface-enhanced Raman scattering and biophysics," Journal of Physics Condensed Matter, vol. 14, no. 18, pp. R597-R624, 2002.

[12] C. M. Aikens and G. C. Schatz, "TDDFT studies of absorption and SERS spectra of pyridine interacting with Au20," Journal of Physical Chemistry A, vol. 110, no. 49, pp. 13317-13324, 2006.

[13] R. L. Birke, V. Znamenskiy, and J. R. Lombardi, "A chargetransfer surface enhanced Raman scattering model from timedependent density functional theory calculations on a Ag10 pyridine complex," Journal of Chemical Physics, vol. 132, no. 21, Article ID 214707, 2010.

[14] A. R. Tao, S. Habas, and P. Yang, "Shape control of colloidal metal nanocrystals," Small, vol. 4, no. 3, pp. 310-325, 2008.

[15] E. Proniewicz, E. Pieta, A. Kudelski et al., "Vibrational and theoretical studies of the structure and adsorption mode of $\mathrm{m}$ nitrophenyl a-guanidinomethylphosphonic acid analogues on silver surfaces," Journal of Physical Chemistry A, vol. 117, pp. 4963-4972, 2013.

[16] N. Piergies, E. Proniewicz, Y. Ozaki, Y. Kim, and L. M. Proniewicz, "Influence of substituent type and position on the adsorption mechanism of phenylboronic acids: infrared, Raman, and surface-enhanced Raman spectroscopy studies," Journal of Physical Chemistry A, vol. 117, no. 27, pp. 5693-5705, 2013.

[17] E. Proniewicz, Y. Ozaki, Y. Kim, and L. M. Proniewicz, “Adsorption mode of neurotensin family peptides onto a colloidal silver surface: SERS studies," Journal of Raman Spectroscopy, vol. 44, no. 3, pp. 355-361, 2013.

[18] E. Proniewicz, N. Piergies, Y. Ozaki, Y. Kim, and L. M. Proniewicz, "Investigation of adsorption mode of a novel group of N-benzylamino(boronphenyl)methylphosphonic acids using SERS," Spectrochimica Acta A: Molecular and Biomolecular Spectroscopy, vol. 103, pp. 167-172, 2013. 
[19] N. Piergies, E. Proniewicz, A. Kudelski et al., "Fourier transform infrared and Raman and surface-enhanced Raman spectroscopy studies of a novel group of boron analogues of aminophosphonic acids," Journal of Physical Chemistry A, vol. 116, no. 40, pp. 10004-10014, 2012.

[20] E. Podstawka-Proniewicz, A. Kudelski, Y. Kim, and L. M. Proniewicz, "Adsorption of neurotensin-family peptides on SERS-active Ag substrates," Journal of Raman Spectroscopy, vol. 43, no. 9, pp. 1196-1203, 2012.

[21] B. Boduszek, T. Olszewski, W. Goldeman, and M. Konieczna, "Aminophosphinic acids in a pyridine series: cleavage of pyridine-2- and pyridine-4-methyl(amino)phosphinic acids in acidic solutions," Phosphorus, Sulfur and Silicon and the Related Elements, vol. 181, no. 4, pp. 787-795, 2006.

[22] W. Goldeman, T. K. Olszewski, B. Boduszek, and W. SawkaDobrowolska, "Aminophosphine oxides in a pyridine series. Studies on the cleavage of pyridine-2- and pyridine-4-yl( $N$-benzylamino)-methyldiphenylphosphine oxides in acidic solutions," Tetrahedron, vol. 62, no. 18, pp. 4506-4518, 2006.

[23] E. Proniewicz, E. Pięta, K. Zborowski et al., "Surfaceenhanced Raman scattering and the adsorption behavior of (diphenylphosphoryl)(pyridin-2, -3, and -4-yl)methanol onto different silver surfaces," Journal of Physical Chemistry A. Accepted.

[24] E. Podstawka, T. K. Olszewski, B. Boduszek, and L. M. Proniewicz, "Adsorbed states of phosphonate derivatives of $\mathrm{N}$-heterocyclic aromatic compounds, imidazole, thiazole, and pyridine on colloidal silver: comparison with a silver electrode," Journal of Physical Chemistry B, vol. 113, no. 35, pp. 12013-12018, 2009.

[25] E. Podstawka, A. Kudelski, T. K. Olszewski, and B. Boduszek, "Surface-enhanced Raman scattering studies on the interaction of phosphonate derivatives of imidazole, thiazole, and pyridine with a silver electrode in aqueous solution," Journal of Physical Chemistry B, vol. 113, no. 29, pp. 10035-10042, 2009.

[26] T. D. Klots, "Raman vapor spectrum and vibrational assignment for pyridine," Spectrochimica Acta A: Molecular and Biomolecular Spectroscopy, vol. 54, no. 10, pp. 1481-1498, 1998.

[27] Z. Zhang, T. Imae, H. Sato, A. Watanabe, and Y. Ozaki, "Surfaceenhanced Raman scattering and surface-enhanced infrared absorption spectroscopic studies of a metalloporphyrin monolayer film formed on pyridine self-assembled monolayermodified gold," Langmuir, vol. 17, no. 15, pp. 4564-4568, 2001.

[28] M. Muniz-Miranda, G. Cardini, and V. Schettino, "Surfaceenhanced Raman spectra of pyridine and pyrazolide on silver colloids: chemical and electromagnetic effects," Theoretical Chemistry Accounts, vol. 111, no. 2-6, pp. 264-269, 2004.

[29] L. Corrsin, B. J. Fax, and R. C. Lord, "The vibrational spectra of pyridine and pyridine-d5," The Journal of Chemical Physics, vol. 21, no. 7, pp. 1170-1176, 1953.

[30] C. H. Kline Jr. and J. Turkevich, "The vibrational spectrum of pyridine and the thermodynamic properties of pyridine vapors," The Journal of Chemical Physics, vol. 12, no. 7, pp. 300309, 1944.

[31] G. S. Kürkçüoğlu, T. Arslan, and C. Öğretir, "Theoretical studies of the molecular structure and vibrational spectra of some dimethyl substituted pyridine derivatives," Journal of Molecular Modeling, vol. 15, no. 1, pp. 79-90, 2009.

[32] F. Partal, M. Fernández-Gómez, J. J. L. López-González, A. Navarro, and G. J. Kearley, "Vibrational analysis of the inelastic neutron scattering spectrum of pyridine," Chemical Physics, vol. 261, no. 1-2, pp. 239-247, 2000.
[33] J. L. Castro, M. R. López Ramírez, I. López Tocón, and J. C. Otero, "Vibrational study of the metal-adsorbate interaction of phenylacetic acid and $\alpha$-phenylglycine on silver surfaces," Journal of Colloid and Interface Science, vol. 263, no. 2, pp. 357363, 2003.

[34] M. Moskovits, "Surface selection rules," The Journal of Chemical Physics, vol. 77, no. 9, pp. 4408-4416, 1982.

[35] P. Gao and M. J. Weaver, "Surface-enhanced Raman spectroscopy as a probe of adsorbate-surface bonding: benzene and monosubstituted benzenes adsorbed at gold electrodes," Journal of Physical Chemistry, vol. 89, no. 23, pp. 5040-5046, 1985. 

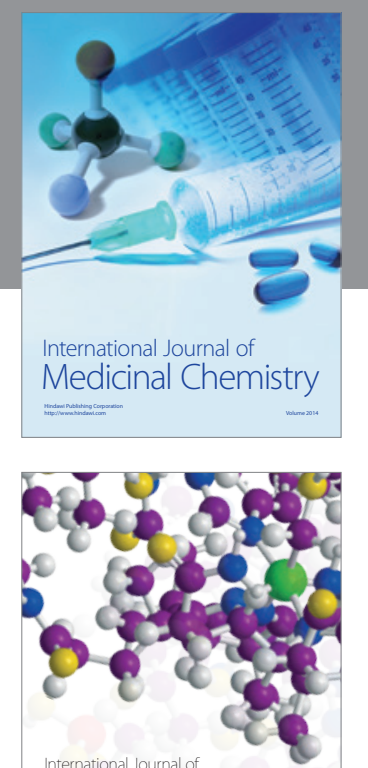

\section{Carbohydrate} Chemistry

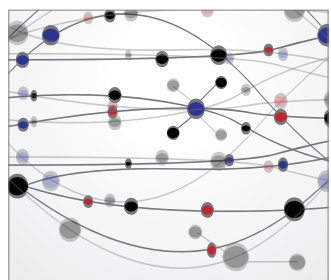

The Scientific World Journal
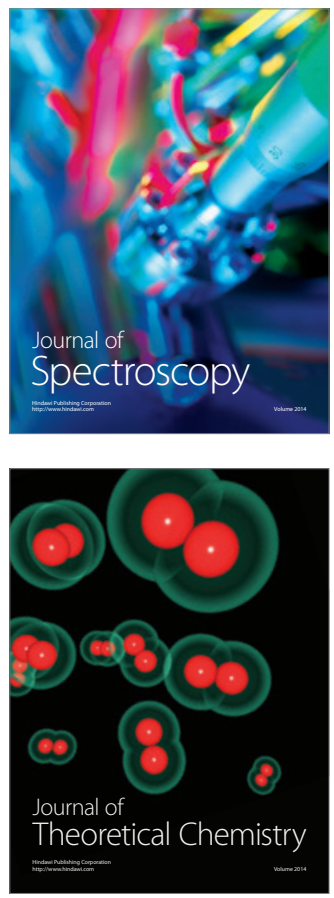
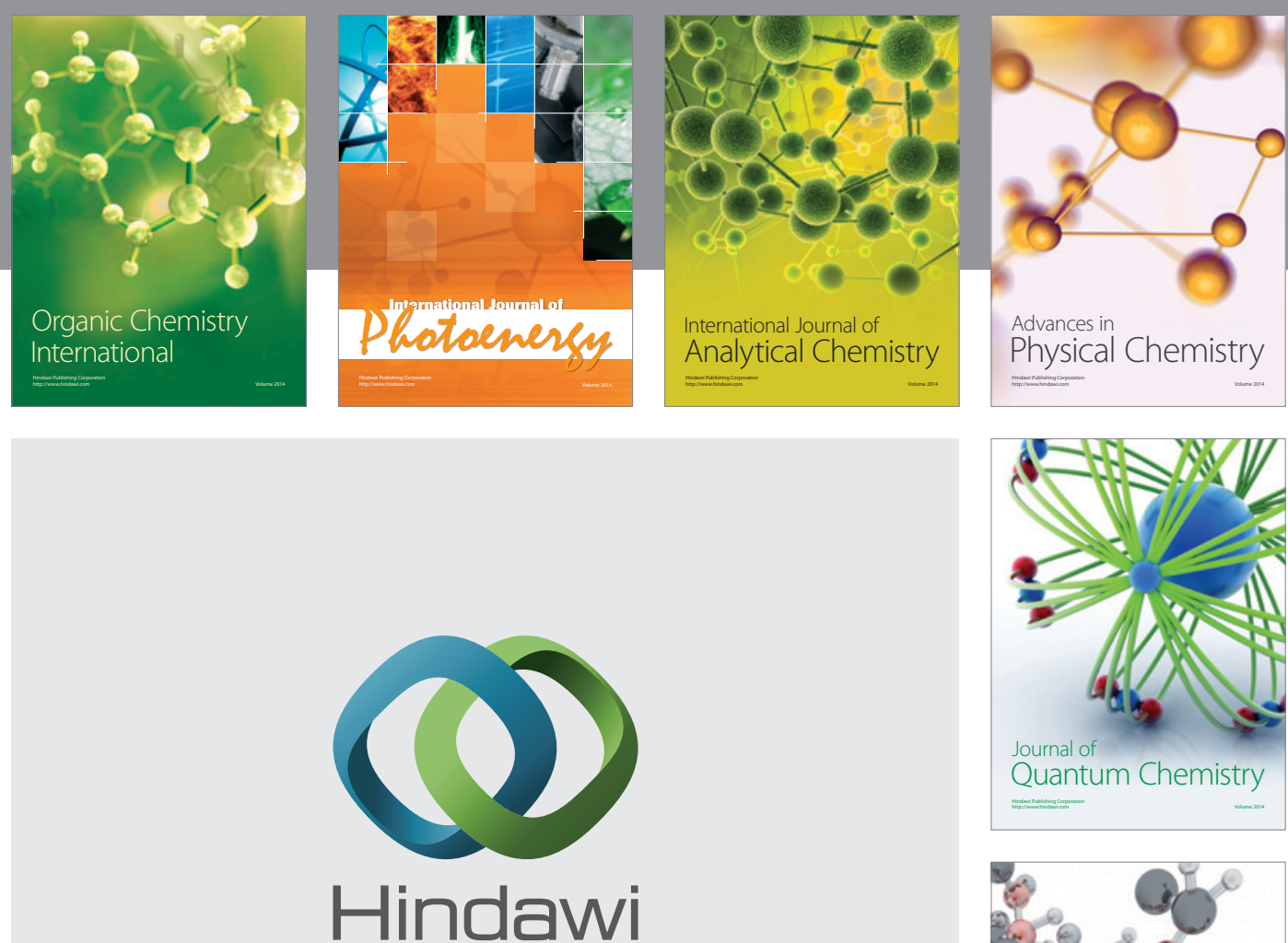

Submit your manuscripts at

http://www.hindawi.com

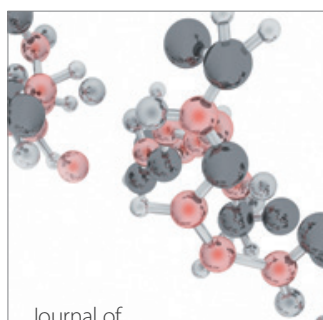

Analytical Methods

in Chemistry

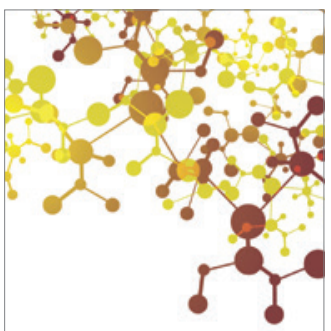

Journal of

Applied Chemistry

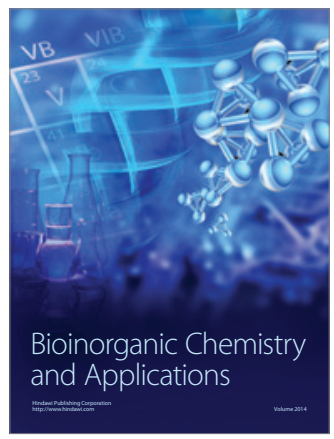

Inorganic Chemistry
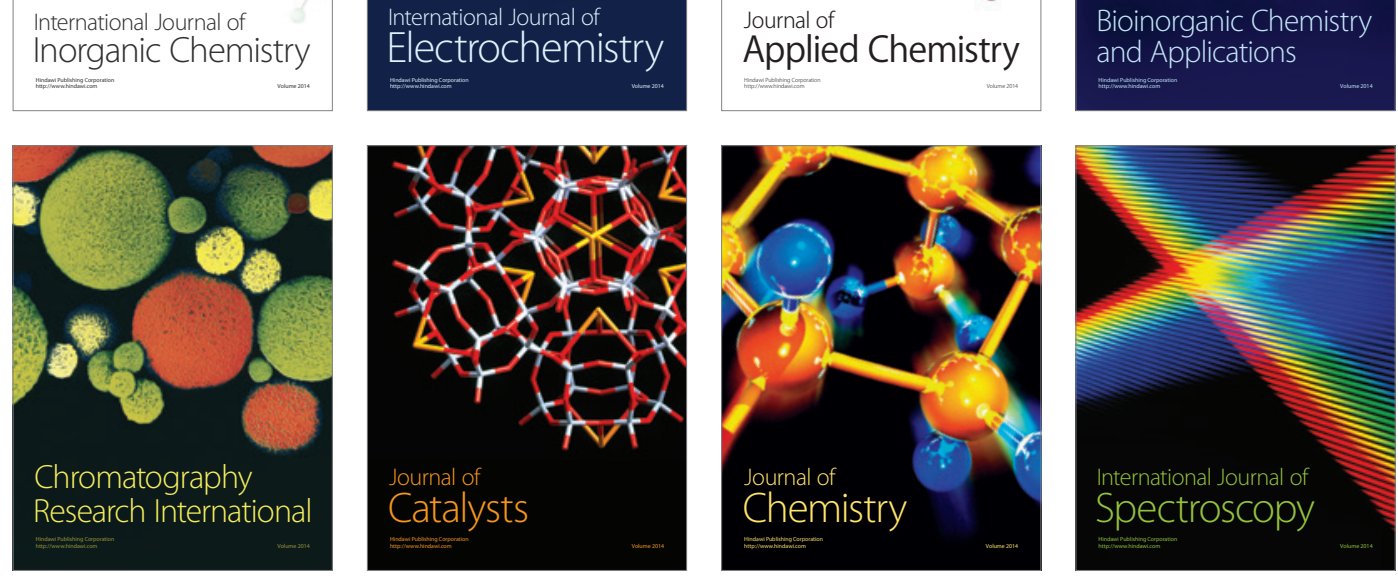